\title{
A135 PERSISTENT TACTILE ALLODYNIA AND SPINAL GLIA ACTIVATION IN THE K/BXN SERUM TRANSFER ARTHRITIS MODEL
}

C A Christianson, M Corr, G S Firestein, T L Yaksh, C I Svensson Karolinska Institutet, Sweden

\subsection{6/ard.2010.129643|}

Chronic pain is a major health problem affecting approximately $20 \%$ of the population resulting in marked reduced quality of life for the individual, as well as extensive costs for society. A large-scale survey undertaken in 15 European countries showed that $40 \%$ of the people who reported persistent pain ( $>6$ months) had joint pain and that osteoarthritis (OA) and rheumatoid arthritis (RA) combined was the most common cause of pain (42\%). 1 Preclinical studies of pain mechanisms in RA have been complicated by the use of different animal models. Common models of inflammation used in pain research often deviate from human rheumatic pathology. The aim of this work was to characterise the pain profile of the $\mathrm{K} / \mathrm{BxN}$ serum transfer arthritis model, a model that is popular in the rheumatology field. Thus, we have undertaken to assess (1) pain behaviour (tactile and thermal), (2) pharmacological responsiveness (tumour necrosis factor (TNF blockade), non-steroidal antiinflammatory drugs (NSAIDs) and gabapentin), and (3) spinal cord non-neuronal cell changes concordant with clinical and histological joint changes in the $\mathrm{K} / \mathrm{BxN}$ serum transfer arthritis model.

Experimental protocols were approved by the Institutional Animal Care Committee. Male C57Bl/6 mice were injected (ip) on days 0 and 2 with $100 \mu 1$ pooled $\mathrm{K} / \mathrm{BxN}$ sera which conferred an acute antibody-mediated inflammatory arthritis. Mice were serially assessed for changes in ankle thickness with calipers and joint swelling was visually scored. Tactile allodynia was determined by using the up-down method of von Frey hair application and thermal escape by using a modified Hargreaves escape model. Arthritic mice displayed significant clinical signs including joint swelling, inflammation and redness of the paw from days $1-12$ post serum transfer $(p<0.05-0.001)$. The mice displayed a significant tactile allodynia from days 2 through day $28(p<0.05-0.001)$. This model displayed no thermal hyperalgesia but a modest hypoalgesia on days $4-6(p<0.001)$. The allodynia present on days $4-10$ was 
reduced by ip etanercept $(5 \mathrm{mg} / \mathrm{kg}$ ) and gabapentin $(100 \mathrm{mg} /$ $\mathrm{kg})$ and ketorolac $(7.5 \mathrm{mg} / \mathrm{kg})$ during a 4-hour time course following dosing. Knee joint histopathology indicates marked inflammatory cell infiltration and moderate bone remodelling. Our data suggest that the $\mathrm{K} / \mathrm{BxN}$ serum transfer mouse provides a polyarticular robust murine arthritis model readily applicable to pain behaviour analysis.

Supported by: Swedish Research Council (CIS), Marie Curie International Reintegration grant (CIS), International Association for Studies of Pain (CIS), Olle Engkvist byggmästare foundation (CIS) and NIH: NS16541 (TLY), DA02110 (TLY), DA21654 (CIS).

\section{REFERENCES}

1. Breivik et al. Eur J Pain $2006 ; \mathbf{1 0} 287-333$. 